\title{
THE EFFECT OF LASER GROOVED IMPLANT RETAINED OVERDENTURE ON BONE HEIGHT CHANGES ORIGINAL ARTICLE
}

\author{
Sonal Abdel Baseer", Hussein El Charkawi** and Mohamed Doheim**
}

\begin{abstract}
Purpose: The aim of the study was to evaluate the crestal bone height changes around laser grooved implants with mandibular overdenture.

Materials and Methods: The study sample comprised of 10 completely edentulous male patients with age range between 40-60 years. In each patient, two laser grooved implants were placed in the interforaminal area. Implants were exposed after three months of healing, and ball abutments were used to retain the mandibular dentures. Crestal bone changes were evaluated using long cone paralleling technique after 0,6 and 12 months. Data were collected, tabulated and statistically evaluated.
\end{abstract}

Results: The results showed that mean change in marginal bone height throughout the 12 months follow-up period was $1.12 \mathrm{~mm}$. T-test showed insignificant difference regarding effect of time on bone height changes from baseline to 6 months, from 6 months to 12 months, and from baseline to $12 \mathrm{~m}$ as $\mathrm{P}>0.05$,

Conclusion: From the results of this study, it could be concluded that laser grooved implant retained overdenture showed minimal bone height changes after 1 year from prosthetic loading.

KEYWORDS: Prosthesis, overdenture, crestal bone, dental implants laser surface treatment

\footnotetext{
* Assistant lecturer, Prosthodontics Dept. Faculty of Oral and Dental Medicine, Future University in Egypt, Cairo, Egypt

** Professor and Chairman of Prosthodontics Dept. Faculty of Oral and Dental Medicine, Future University in Egypt, Cairo, Egypt

*** Lecturer, Prosthodontics Dept. Faculty of Oral and Dental Medicine, Zagazig University, Egypt
} 


\section{INTRODUCTION}

Edentulous patient usually suffer from lack of optimal stability and retention especially with their mandibular dentures in cases of severely resorbed ridges. Implant retained overdenture is considered a reliable treatment modality that contributes to a more favorable and successful prosthesis. It provides better chewing and masticatory performance, less complaints and higher satisfaction when compared with conventional complete denture. ${ }^{[1-3]}$

Until the 1990s, dental implants had primarily machined smooth surfaces. Imperfections along these machined surfaces enable osteogenic cells to attach and to deposit bone. Implants with smooth machined surface have the disadvantage of requiring long time for osseointegration, about 3 to 6 months depending on the anatomical location and the quality of bone. ${ }^{[4]}$ Titanium implant surfaces have been modified in various ways to improve biocompatibility and accelerate osseointegration, which results in a shorter treatment time period for a patient. ${ }^{[5]}$

The surface modification methods can be divided into subtractive and additive methods. The subtractive methods remove material from the implant surface, such as grit blasting, acid etching, anodization and laser ablation. Whereas the additive methods add material, by methods like, hydroxyapatite coating, calcium phosphate coating and recently titanium plasma spraying. ${ }^{[4]}$

Surface roughness can be divided into three levels depending on the scale of the features: Macrosized topography, micro-sized topography and nano-sized topography. The macro topography of an implant is determined by its visible geometry, for example, threaded screws. Numerous reports have shown that appropriate macro topography improves both the primary implant fixation and long-term mechanical stability. ${ }^{[6,7]}$

In recent years, scientific effort was mainly focused on micro- and nanotopography. Microtopog- raphy is linked to microroughness ranging from $(1-100 \mu \mathrm{m})$ and is achieved by fabrication methods like acid-etching, anodization, sandblasting, and different coating materials ${ }^{[8]}$. Implant surfaces with microtopography have shown greater percentage of bone-to-implant contact and higher resistance to torque removal when compared with machined or polished titanium surfaces. ${ }^{[9]}$

While the micro topography of the implant surface has been proposed to act at the cellular level of osseo-integration ${ }^{[10]}$, nano-topography is thought to influence cell-implant interactions at the cellular and protein level ${ }^{[11]}$.

Nano-surface topography scale ranges from 1 to $100 \mathrm{~nm}$. Changes in nanotopography convey their effects at a physical, chemical, and biological level. At the nano-scale, a more textured surface topography increases the surface energy. A high surface energy increases its wettability to blood, and the spreading and binding of fibrin and matrix proteins. It thus favors cell attachment and tissue healing, particularly directly after implantation, which is an important point in the osseointegration process. ${ }^{[4,12]}$

Numerous reports have shown that bone-implant contact, the removal torque values, the early fixation and long-term mechanical stability of the implant can be improved by a high roughness profile compared to smooth surfaces ${ }^{[13,14]}$ However, a major risk with high surface roughness may be an increase in peri-implantitis as well as an increase in ionic leakage. ${ }^{[5,15]}$

Surface treatment by sand blasting implies blasting the implant with hard ceramic particles which are projected through a nozzle at high velocity by means of compressed air. Various ceramic particles have been used, such as alumina, titanium oxide and calcium phosphate particles. Alumina (Al2O3) is frequently used; however it gets impeded in the implant surface. Being insoluble in acids makes it hard to remove from the implant surface. 
These particles can release into the surrounding tissue and interfere with osseointegration. Additionally, the chemical heterogeneity of the implant surface may decrease the excellent corrosion resistance of titanium in a physiological environment. ${ }^{[16]}$

Recently, the technique of blasting followed by acid etching has been commonly used for surface treatment. Blasting achieves a favorable roughness, while the acid etching smoothness the peaks and increases protein adherence, which is considered important during the initial bone healing process. ${ }^{[17]}$

Another possibility for roughening titanium dental implants consists of using a biocompatible, osteoconductive and resorbable blasting material like calcium phosphate and hydroxyapatite and beta-tricalcium phosphate. Unlike alumina; they are resorbable and easy to remove from the implant surface without the need to strong acids. Leading to, clean implants without contamination from acids. ${ }^{[18]}$

Laser ablation was suggested by many authors to mechanically create surface roughness. Laser can produce micro- or nano-roughness. Laser has many advantages over the other mechanical methods used to create surface roughness such as, the ability to create topography of uniform size and shape; also it is a very reproducible roughness. Laser acts in a no contact mode leading to contamination-free implants. ${ }^{[19]}$

In a study done by Branemark et al ${ }^{[20]}$ they evaluated the biomechanical and histological bone response to laser-induced micro- and nano-scale implant surface roughness in comparison with machined implants. After an early 8 -week healing period in rabbit tibia and femur, a $250 \%$ increase in removal torque was demonstrated for the lasertreated implants. Histologically, significantly more bone was found in direct contact with the lasermodified surface for the implants. They concluded that the micro- and nano- surface roughness and surface oxide formed by laser treatment increased the amount of bone formed in direct contact with the implant.

Soft tissues attachment to laser microgrooved titanium abutment surfaces was examined histologically and microscopically by polarized light and scanning electron microscopy. After 6 months of healing, perpendicular collagen fiber bundles was attached mechanically on the laser treated surfaces. ${ }^{[21]}$

Numerous studies also reported shallower pocket depth and less peri-implant crestal bone loss around laser surface treated implants when compared to machined implants, ${ }^{[22-25]}$ and faster osseointegration. ${ }^{[26]}$

\section{AIM OF THE STUDY}

The aim of the study was to evaluate the bone height changes around laser grooved implants supporting mandibular overdenture after one year of loading.

\section{MATERIALS AND METHODS}

Ten healthy completely edentulous male patients were selected with age range 40-60 years from the clinics of Faculty of Oral and Dental Medicine, Future University in Egypt. All patients selected were healthy and have well keratinized mucosa, bone width of $8 \mathrm{~mm}$ and bone height to accommodate $10 \mathrm{~mm}$ implant (Biomate implant system, Biomate Medical Devices, Taiwan). The selected patients were aware of the nature of the research work and patient's approval was obtained by written consensus. The research work was approved by Future university ethics committee, approval number FUE. REC (10)/10-2017. Participant flowchart is shown in figure (1).

After clinical and pre-operative radiographic assessment with panoramic radiograph, all patients received a new conventional complete denture. 


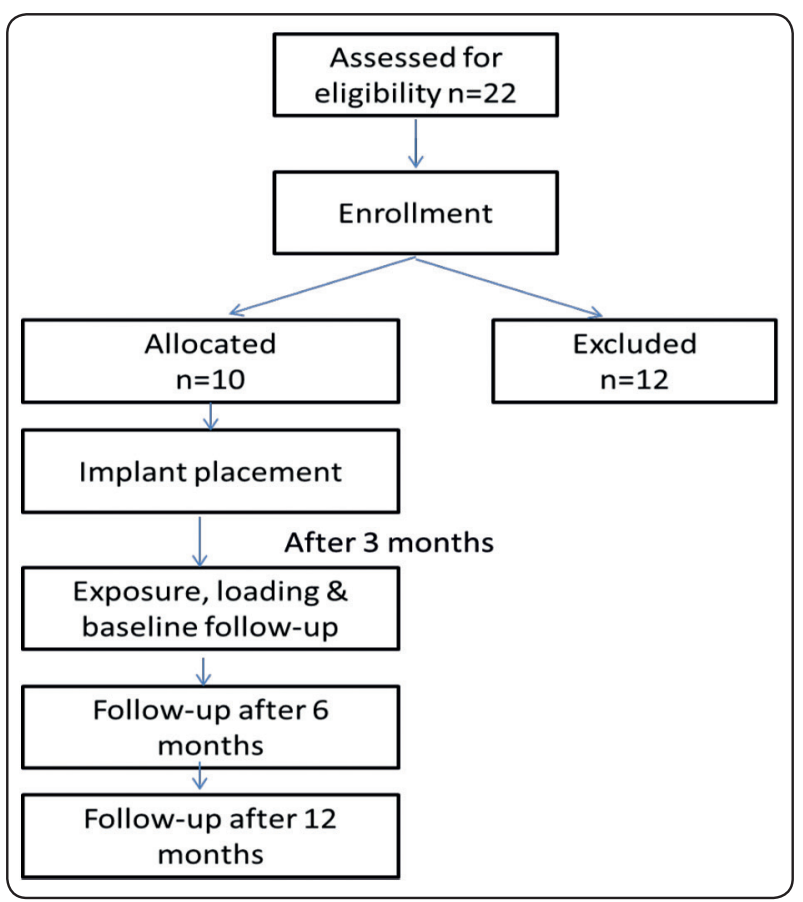

Fig. (1) Participant flowchart

\section{Scan appliance construction:}

A scan appliance of the finished denture was constructed to be worn by the patients during the CBCT scan to aid in CBCT interpretation. The denture was duplicated in a radiopaque material using a mix of self-cure acrylic resin (Cold cure special tray material, Acrostone, Egypt)- and barium sulphate (12\%). Holes were drilled in the surgical guide in the proposed implant positing between lower lateral and lower canine ${ }^{[27]}$ as shown in figure (2).

For each patient, following clinical and radiographic examination, two root form dental implants with internal hex, $10^{\circ}$ Morse taper, trapezoid self-tapping thread design with thread depth of $0.3 \mathrm{~mm}$ and laser surface treatment was selected (Biomate implant system, Biomate Medical Devices, Taiwan). The implants were $\varnothing 4.1$ in diameter and $10 \mathrm{~mm}$ in length.

This radiographic guide was then converted into a surgical guide by reducing anterior teeth height and anterior labial flange as shown in figure (3).

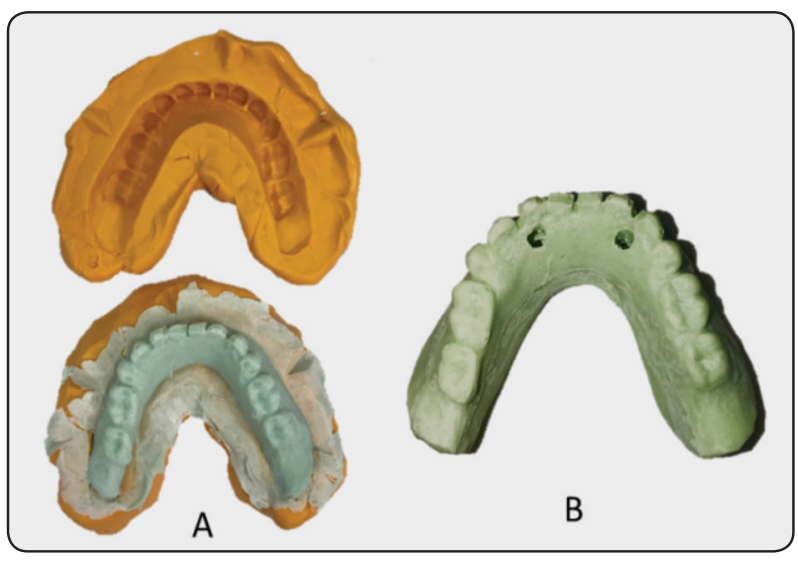

Fig. (2) (A) Denture duplication (B) Scanning appliance.

\section{Surgical Preparation \& Procedure}

One hour pre-operative, Amoxicillin was administered as prophylactic antibiotic. Mandibular mental block anesthesia and infiltration was given bilaterally using Mepivacaine-L 2\% carpule (MepecainL, AlexandriaCo. Pharmaceuticals, Egypt). After confirming that the tissues were anaesthetized, the surgical stent was introduced and bleeding points was done by probe in the proposed implant sites.

Using a No. 15 surgical Bard-Parker blade (SteriLance Medical, Suzhou Inc, Jiangsu, China) a crestal incision was performed down to the bone extending $1 \mathrm{~cm}$ distal to the proposed implants sites. A full thickness mucoperiosteal flap was elevated labially and lingually. Handpiece torque and rpm setting was set according to the manufacturer instructions.

Drilling was done insuring parallelism between the osteotomies. After completion of the preparation the implants were carried out of its sterile vial and screwed until resistance is felt, then the Torque Ratchet (Biomate implant system, Biomate Medical Devices, Taiwan) was used to complete the implant insertion to the full depth until the implant top was below the bone surface and adequate torque of minimum $35 \mathrm{Ncm}$ achieved, cover screw was threaded into the implant and finally, the flap was repositioned and secured by interrupted suture and 
horizontal mattress suture using 4/0 black silk suture (International Sutures Manufacturing Co., Egypt).

Patient was instructed to bite down on sterile gauze pack soaked in saline (Sterile sodium chloride $0.9 \%$, FIPCO, Egypt) for 30 minutes to ensure that any post-operative bleeding stops. Post-operative instructions were given. The patients were recalled after two weeks for suture removal.

\section{Abutment connection and loading}

After 3 months of healing, implants were exposed and healing collars were screwed into the implants. Then the two implants were tested for signs of successful osseointegration.

The areas opposing the healing collar on the denture fitting surface was marked and relieved by acrylic stone to allow seating of the denture and tissues were left to heal for two weeks. After two weeks, healing collars were removed and implants were loaded by ball abutments.

\section{Follow-up}

Changes in crestal bone height were evaluated radiographically by long cone paralleling technique at time of loading (baseline), 6 months and 12 months using VistaScan imaging plate (VistaScan Imaging plate Size 0, DURR DENTAL SE, Germany).

For each patient, a radiographic stent was constructed on a cast obtained from an open tray impression by modifying the anterior RINN XCP film holder which was modified by trimming the vertical part to accommodate the limited lingual vestibule of the completely edentulous patients and drilling a hole in the horizontal part to fit the impression coping. Vertical part of the film holder was adjusted parallel to the implant long axis as shown in figure (4). Stents were screwed into the implants as shown in figure (5). Changes in bone height were calculated digitally from a reference line at implant abutment junction and a line tangential to the implant as shown in figure (6). Data were tabulated and statistically analyzed using repeated one way ANOVA measures.

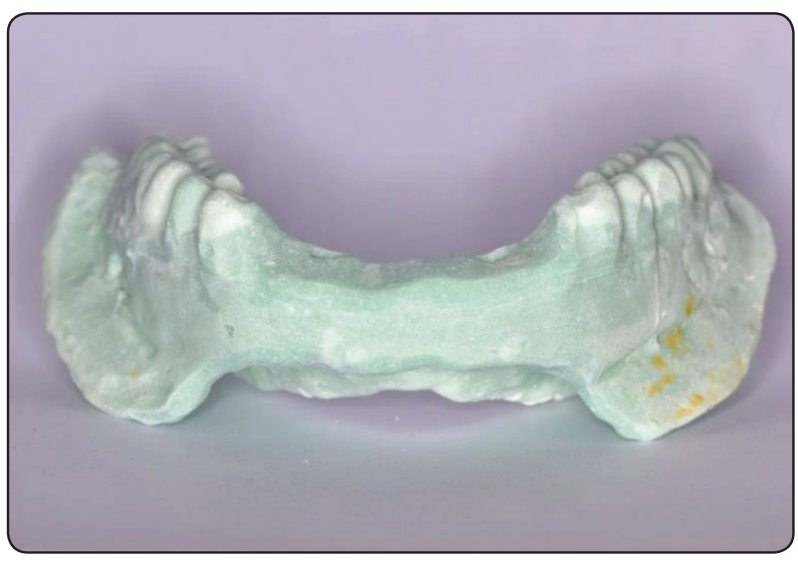

Fig. (3) Scan appliance converted to surgical guide by reduction of anterior teeth height and anterior labial flange

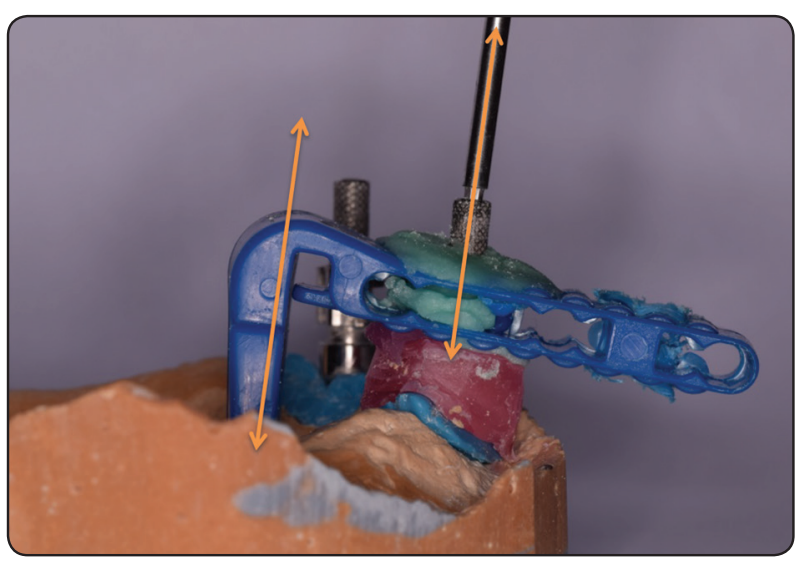

Fig. (4) Showing parallelism between the implant long axis and the vertical part of the film holder

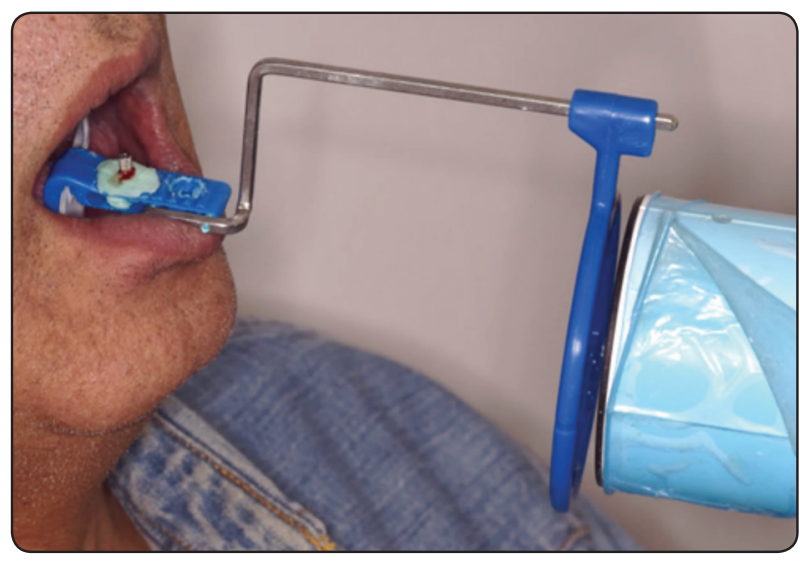

Fig. (5) The radiographic stent screwed onto the implant during exposure 


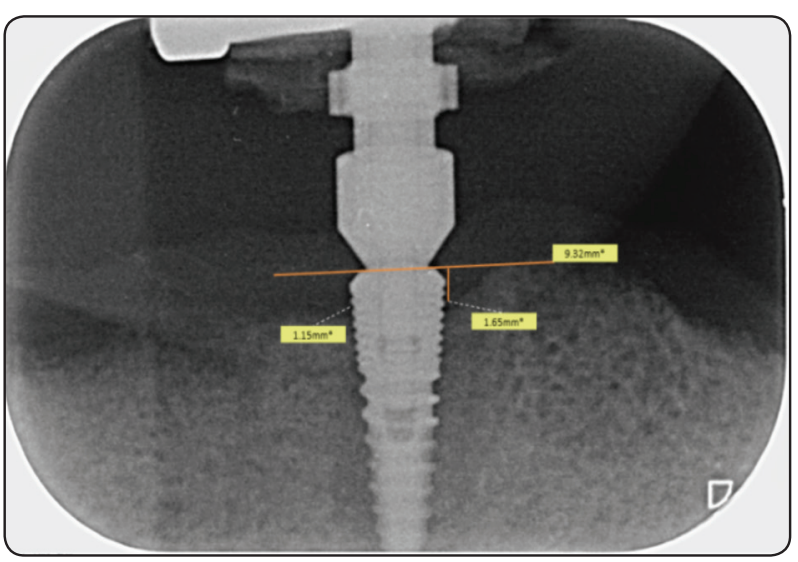

Fig. (6) Showing measuring crestal bone height changes from horizontal reference line at implant abutment junction.

\section{RESULTS}

Comparison was performed between different follow up periods by performance on repeated one way ANOVA measures which revealed insignificant difference between them as $\mathrm{p}>0.05$.

$\mathrm{T}$ test showed insignificant difference regarding effect of time on bone height changes from baseline to 6 months, from 6 months to 12 months, and from baseline to $12 \mathrm{~m}$ as $\mathrm{P}>0.05$, as presented in table (1) fig. (7).

TABLE (1)

\begin{tabular}{|c|c|c|c|c|}
\hline & $\mathrm{M}$ & $\mathrm{SD}$ & $\mathrm{T}$ value & P value \\
\hline $\begin{array}{c}\text { At base line } \\
\text { - After 6 months }\end{array}$ & 0.10 & 0.03 & 0.82 & 0.20 \\
\hline $\begin{array}{c}\text { After 6 months } \\
\text { - After 12 months }\end{array}$ & 0.07 & 0.02 & 0.60 & 0.27 \\
\hline $\begin{array}{c}\text { At baseline } \\
\text {-After 12 months }\end{array}$ & 0.17 & 0.01 & 1.39 & 0.08 \\
\hline
\end{tabular}

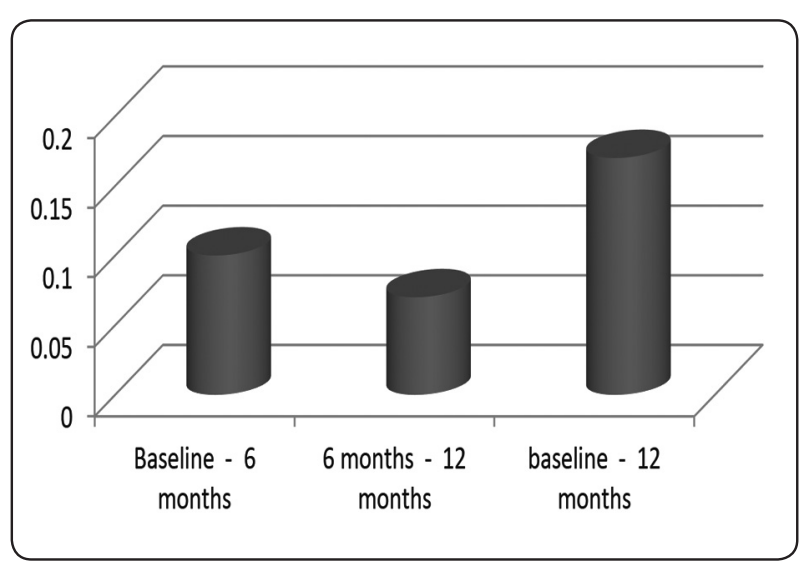

Fig. (7) Bone changes at different time intervals.

\section{DISSCUSION}

All patients attended all the follow-up recalls till the end of the study (one year). All implants showed successful osseointegration.

In this study, the results showed mean change in marginal bone loss through the 12 months followup period was $1.12 \mathrm{~mm}$. The recorded values were consistent with those reported by other authors who done similar studies ${ }^{[28-32]}$

Buser et al ${ }^{[33]}$ and Albrektsson and Zarb ${ }^{[34]}$ reported implant success criteria which includes that crestal bone loss remain less than $1.5 \mathrm{~mm}$ after the first year of loading. However, a loss of more than $0.2 \mathrm{~mm}$ per year thereafter is regarded as undesirable.

The minimal mean crestal bone height changes values reported in this study after one year of loading could be attributed to the effect of dental implant laser surface treatment among other factors on improvement of osseointegration and crestal bone height in agreement with other studies ${ }^{[21-25,35-37]}$

Not only laser grooved dental implants reduce crestal bone loss, but also laser microgrooves appear to inhibit apical migration of cervical epithelium and to promote true attachment of peri-implant gingiva. Forming an interface between connective 
tissue and the implant collar that is more like the biological width attachment of natural teeth, which will improve the long-term performance of dental implants by decreasing crestal bone loss, as reported by Ketabi et al ${ }^{[23]}$ and other authors ${ }^{[21,24,36,40,42]}$.

\section{CONCLUSION}

Within the limitation of this one year clinical study it can be concluded that, laser grooved implants retaining overdentures showed minimal bone height changes after 1 year from prosthetic loading. The clinical use of dental implants with laser surface treatment and nano-topography to retain mandibular overdenture could be used predictably for edentulous patients.

Further long term comparative clinical studies with different implant surface treatments and larger sample sizes should be performed.

\section{Conflict of Interest}

The authors declare no conflict of interests

The authors received no specific funding for this work.

\section{REFERENCES}

1. Sharma R, Kumar A, Chopra D, et al. Implant-supported overdenture. J Dent Sci Oral Rehab 2014; 5: 139-41.

2. Misch, Carl E. The Edentulous Mandible: Treatment Plans for Implant Overdentures. Dental implant prosthetics 2014; 573-599.

3. Thomason JM, Feine J, Exley C, et al. Mandibular two implant-supported overdentures as the first choice standard of care for edentulous patients--the York Consensus Statement. Br Dent J. 2009; 207: 185-6.

4. Smeets R, Stadlinger B, Schwarz F, et al. Impact of dental implant surface modifications on osseointegration. Biomed Res Int 2016.

5. Le Guéhennec L, Soueidan A, Layrolle P, et al. Surface treatments of titanium dental implants for rapid osseointegration. Dent Mater 2007; 23: 844-54.

6. Wennerberg A, Hallgren C, Johansson C, et al. A histomorphometric evaluation of screw-shaped implants each prepared with two surface roughnesses. Clin Oral Implants Res. 1998; 9: 11-9.

7. Dos Santos MV, Elias CN, Cavalcanti Lima JH. The effects of superficial roughness and design on the primary stability of dental implants. Clin Implant Dent Relat Res. 2011; 13: 215-23.

8. Dohan Ehrenfest DM, Coelho PG, Kang BS, et al. Classification of osseointegrated implant surfaces: materials, chemistry and topography. Trends Biotechnol. 2010; 28: 198-206.

9. Schwartz Z, Nasazky E, Boyan BD. Surface microtopography regulates osteointegration: the role of implant surface microtopography in osteointegration. Alpha Omegan. 2005; 98: 9-19.

10. Rupp F, Scheideler L, Rehbein D, et al. Roughness induced dynamic changes of wettability of acid etched titanium implant modifications. Biomaterials. 2004; 25: 1429-38.

11. Mendonça G, Mendonça DB, Aragão FJ, et al. Advancing dental implant surface technology from micron- to nanotopography. Biomaterials. 2008; 29: 3822-35.

12. Rosa MB, Albrektsson T, Francischone CE, et al. The influence of surface treatment on the implant roughness pattern. J Appl Oral Sci. 2012; 20: 550-5.

13. Wennerberg A, Ektessabi A, Albrektsson T, et al. A 1-year follow-up of implants of differing surface roughness placed in rabbit bone. Int $\mathrm{J}$ Oral Maxillofac Implants. 1997; 12: 486-94.

14. Buser D, Schenk RK, Steinemann S, et al. Influence of surface characteristics on bone integration of titanium implants. A histomorphometric study in miniature pigs. J Biomed Mater Res. 1991; 25: 889-902.

15. Rimondini L, Farè $S$, Brambilla E, et al. The effect of surface roughness on early in vivo plaque colonization on titanium. J Periodontol. 1997; 68: 556-62.

16. Aparicio C, Gil FJ, Fonseca C, et al. Corrosion behaviour of commercially pure titanium shot blasted with different materials and sizes of shot particles for dental implant applications. Biomaterials. 2003; 24: 263-73.

17. Wennerberg A, Albrektsson T. Effects of titanium surface topography on bone integration: a systematic review. Clin Oral Implants Res. 2009; 20: 172-84.

18. Pattanaik B, Pawar S, Pattanaik S. Biocompatible implant surface treatments. Indian J Dent Res. 2012; 23: 398-406.

19. Trisi P, Berardini M, Colagiovanni M, et al. Laser-Treated Titanium Implants: An In Vivo Histomorphometric and Biomechanical Analysis. Implant Dent. 2016; 25: 575-80. 
20. Brånemark R, Emanuelsson L, Palmquist A, et al. Bone response to laser-induced micro-and nano-size titanium surface features. Nanomedicine 2011; 7: 220-7.

21. Nevins M, Nevins ML, Camelo M, et al. Human Histologic Evidence of a Connective Tissue Attachment to a Dental Implant. Int J Periodontics Restorative Dent 2008; 28.

22. Botos S, Yousef H, Zweig B, et al. The Effects of Laser Microtexturing of the Dental Implant Collar on Crestal Bone Levels and Peri-implant Health. Int J Oral Maxillofac Implants 2011; 26.

23. Ketabi M, Deporter D. The effects of laser microgrooves on hard and soft tissue attachment to implant collar surfaces: a literature review and interpretation. Int J Periodontics Restorative Dent 2013; 33.

24. Pecora GE, Ceccarelli R, Bonelli M, et al. Clinical evaluation of laser microtexturing for soft tissue and bone attachment to dental implants. Implant Dent 2009; 18: 57-66.

25. Chen Z, Zhang Y, Li J, et al. Influence of Laser-Microtextured Surface Collar on Marginal Bone Loss and PeriImplant Soft Tissue Response: A Systematic Review and Meta-Analysis. J Periodontol. 2017; 88: 651-662.

26. Rong M, Zhou L, Gou Z, et al. The early osseointegration of the laser-treated and acid-etched dental implants surface: an experimental study in rabbits. J Mater Sci Mater Med 2009; 20: 1721-1728.

27. Israelson H, Plemons JM, Watkins $\mathrm{P}$, et al. Barium coated surgical stents and computer-assisted tomography in the preoperative assessment of dental implant patients. Int J Periodontics Restorative Dent 1992; 12.

28. Wang YC, Kan JY, Rungcharassaeng K, et al. Marginal bone response of implants with platform switching and non-platform switching abutments in posterior healed sites: a 1-year prospective study. Clin Oral Implants Res 2015; 26: 220-7.

29. Abrahamsson I, Berglundh T, Lindhe J. The mucosal barrier following abutment dis/reconnection: an experimental study in dogs. J Clin Periodontol 1997; 8: 568-72.

30. Misch CE, Perel ML, Wang HL, et al. Implant success, survival, and failure: the International Congress of Oral Implantologists (ICOI) pisa consensus conference. Implant Dent 2008; 17: 5-15.

31. Goswami MM. Comparison of crestal bone loss along two implant crest module designs. Med J Armed Forces India 2009; 65: 319-22.
32. Adell R, Lekholm U, Rockler BR, et al. A 15-year study of osseointegrated implants in the treatment of the edentulous jaw. Int J Oral Surg 1981; 10: 387-416.

33. Buser D, Weber HP, Brägger U, et al. Tissue integration of one-stage implants: three-year results of a prospective longitudinal study with hollow cylinder and hollow screw implants. Quintessence Int 1994; 25.

34. Albrektsson T, Zarb GA. Determinants of correct clinical reporting. Int J Prosthodont 1998; 11: 517.

35. Xu JY, Chen XS, Zhang CY, et al. Improved bioactivity of selective laser melting titanium: surface modification with micro-/nano-textured hierarchical topography and bone regeneration performance evaluation. Mater Sci Eng C Mater Biol Appl 2016; 68: 229-40.

36. Iglhaut G, Schwarz F, Winter RR, et al. Epithelial attachment and downgrowth on dental implant abutments - a comprehensive review. J Esthet Restor Dent 2014; 26: 324-31.

37. Gaggl A, Schultes G, Müller WD, et al. Scanning electron microscopical analysis of laser-treated titanium implant surfaces - a comparative study. Biomaterials 2000; 21: 1067-73.

38. Götz HE, Müller M, Emmel A, et al. Effect of surface finish on the osseointegration of laser-treated titanium alloy implants. Biomaterials 2004; 25: 4057-64.

39. Faeda RS, Tavares HS, Sartori R, et al. Evaluation of titanium implants with surface modification by laser beam: biomechanical study in rabbit tibias. Braz Oral Res 2009; 23: $137-43$.

40. Shapoff CA, Lahey B, Wasserlauf PA, et al. Radiographic analysis of crestal bone levels around Laser-Lok collar dental implants. Int J Periodontics Restorative Dent 2010; 30.

41. Palmquist A, Grandfield K, Norlindh B, et al. Bone-titanium oxide interface in humans revealed by transmission electron microscopy and electron tomography. J R Soc Interface 2012; 9: 396-400.

42. Farronato D, Mangano F, Briguglio F, et al. Influence of Laser-Lok surface on immediate functional loading of implants in single-tooth replacement: a 2-year prospective clinical study. Int J Periodontics Restorative Dent 2014; 34: 79-89.

43. Lepore S, Milillo L, Trotta T, et al. Adhesion and growth of osteoblast-like cells on laser-engineered porous titanium surface: expression and localization of $\mathrm{N}$-cadherin and beta-catenin. J Biol Regul Homeost Agents 2013; 27: 531-41. 